\title{
VIRTUAL METHOD FOR THE INVESTIGATION OF DYNAMIC EMISSION FORMATION FOR GASOLINE ENGINES $14^{\mathrm{TH}}$ WCCM - ECCOMAS CONGRESS 2020
}

\author{
LENNART MÄHLER ${ }^{1}$, MATTHIEU PROUVIER ${ }^{2}$, \\ PETER KAWELKE ${ }^{3}$ AND AXEL WINKLER ${ }^{4}$ \\ ${ }^{1}$ Volkswagen AG, Berliner Ring 2, 38440 Wolfsburg, lennart.maehler@volkswagen.de \\ ${ }^{2}$ Volkswagen AG, Berliner Ring 2, 38440 Wolfsburg, matthieu.prouvier@volkswagen.de \\ ${ }^{3}$ Volkswagen AG, Berliner Ring 2, 38440 Wolfsburg, peter.kawelke@volkswagen.de \\ ${ }^{4}$ Volkswagen AG, Berliner Ring 2, 38440 Wolfsburg, axel.winkler@volkswagen.de
}

Key words: Transient Simulation, Emission Formation, Internal Combustion Engine CFD.

\begin{abstract}
Significantly reduced development times of today's powertrains as well as steadily increasing requirements regarding fuel consumption and pollutant emissions require a continuous refinement of the development methods for internal combustion engines. The presented simulation method focuses on the new and tightened approval cycles for passenger car engines; more particularly on the start-up phase as well as on sharp load changes, which lead to increased engine out emissions.

The aim of this study is to create a simulation tool for the investigation and the evaluation of the emissions during the dynamic engine operation. Established simulation methods, such as Computational Fluid Dynamics (CFD), are bundled in such a way that transient processes can be simulated within a reasonable calculation time without significant loss of information. The tool is based on a 1D gas exchange simulation software. Herein, detailed reaction kinetics are used to simulate the combustion process, which also takes the thermal boundary conditions (wall temperatures) and the quality of the mixture formation into account. For this purpose, the gas exchange model is extended with a thermal network and the mixture formation process is assessed with CFD. Suitable test bench data serve to validate the whole process chain.

In addition to the improvement of the CAE-based assessment for the development of virtual engines, the simulation tool should provide an understanding of the phenomena leading to emission formation under the transient engine operation. Furthermore, using such a tool can contribute to the development of alternative driving concepts like plug-in hybrid electric vehicles (PHEV) and exhaust aftertreatment systems.
\end{abstract}




\section{INTRODUCTION}

The importance of the individual traffic is growing continuously. Between 1995 and 2018, the total $\mathrm{CO}_{2}$ emissions in the passenger car sector have increased by 3.7 percent, while the specific $\mathrm{CO}_{2}$ emissions were reduced by 9 percent in the same period of time. This increase is caused by traffic growth of 14 percent [1]. The production of cars and light commercial vehicles increases annually. In 2015, 89.05 million light vehicles were produced, while the forecast for 2026 expects a production rate of 117.28 million light vehicles (information as of June 2020). This corresponds with an annual increase of around 1.6 percent [2]. Against this backdrop, the global $\mathrm{CO}_{2}$ emissions will continue to increase during the next years.

Besides this, further emissions are produced during the combustion process, which also are regulated by legislation. The current legislation is based on the Euro 6 standard (see table 1). In the future these regulations will be tightened significantly.

Table 1: Emission limits for passenger cars with gasoline engines according to Euro 6 standard
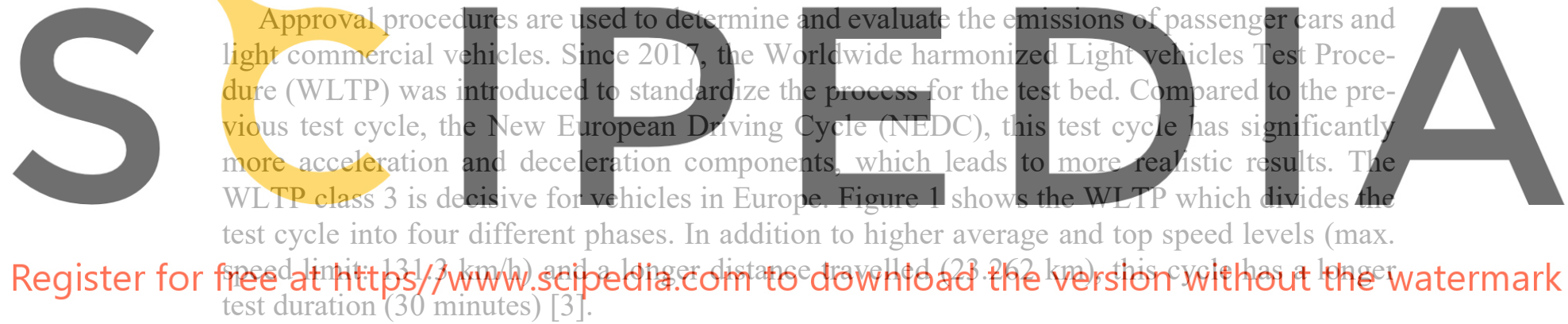

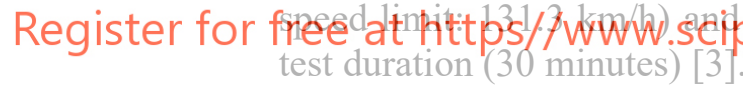

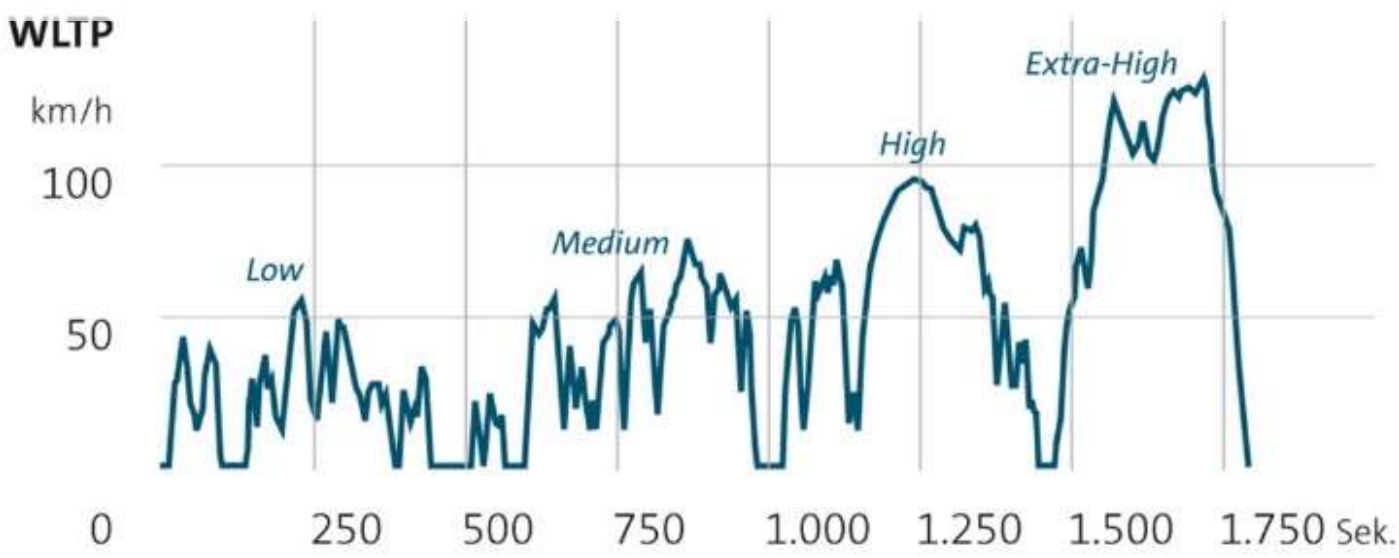

Figure 1: Vehicle velocity profile for WLTP class 3 [4] 
Considering stricter emission limits, car manufacturers have to find ways to optimize the internal combustion engine that will result in a significant reduction of fuel consumption and pollutant emissions. Especially cold starts and sharp changes in torque in the acceleration phases are responsible for high emissions. At the same time the available development time for new engines gets shorter and shorter. In order to achieve this goal, simulation tools must also be improved and refined. Due to the current computer technology with higher computing power and storage technology, the simulation offers big advantages to calculate emission formation in satisfactory accuracy.

The aim is to create a simulation tool that can determine the emissions under transient engine conditions. In addition to an understanding of the generation of emissions under these conditions, the simulation environment offers the opportunity to develop alternative engine control strategies. Furthermore, the simulation of new gas aftertreatment concepts can be supported with such a simulation tool. This leads to cost and time savings in the development process of future driving concepts.

\section{SIMULATION ENVIRONMENT}

Attempts are made to determine the emissions in the engine development process early and precisely. Sometimes improvements require hundreds or thousands of experiments. Therefore, simulation tools areused, which can assess the impact of such experiments in a time-saving and

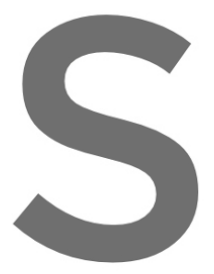
cost-effective way

In this research sions formation during the transient engine ope are coupled to exainine and evaluate the engine emissions aim of the simulation tool is to deliver adequate results in an industrial time frame. Figure 2

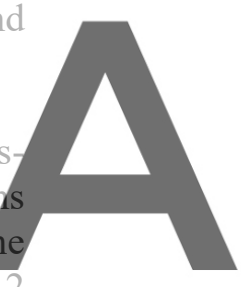
shows the concept of the simulation tool, which is presented in more detail in this chapter. Register for free at https//www.scipedia.com to download the version without the watermark

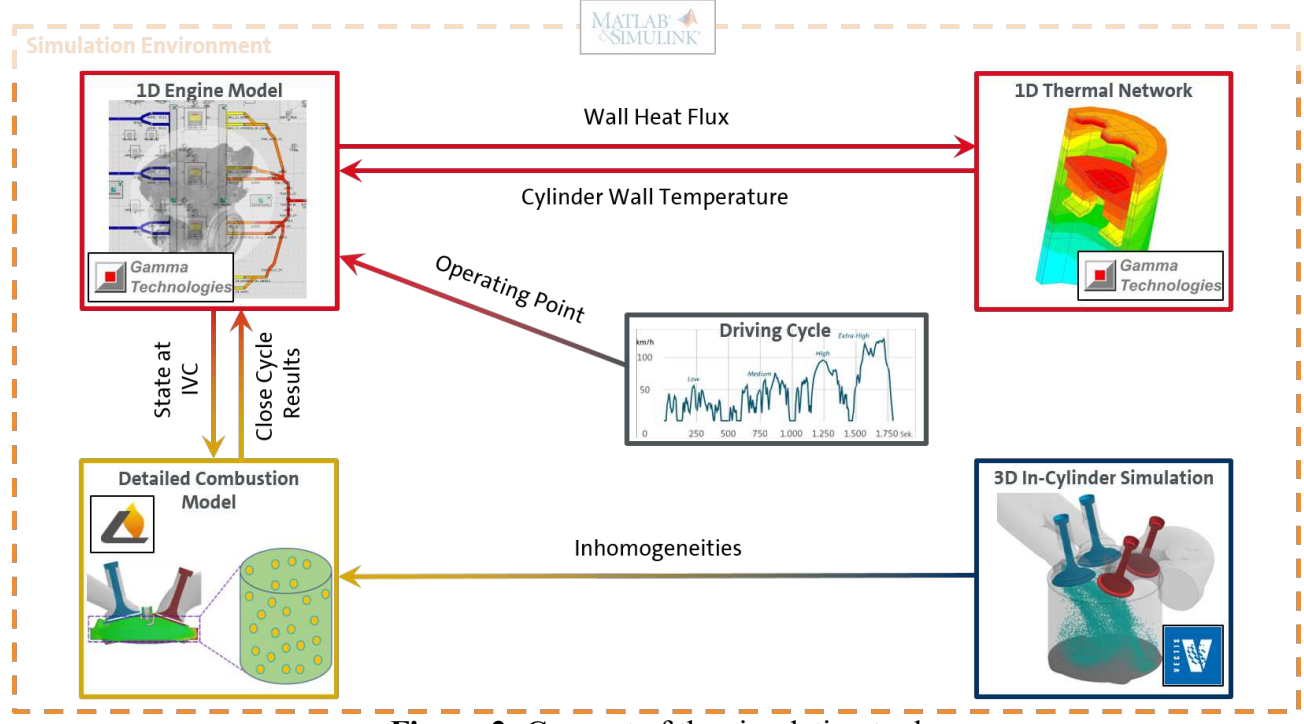

Figure 2: Concept of the simulation tool 
Such a simulation tool can be used to understand the highly complex phenomena of pollutant generation in transient engine operation. Hereby, cold starts and highly dynamic engine operating conditions lead to high emission peaks. The simulation tool combines the following simulation approaches:

- 1D Engine Model: Represents the digital version of the engine with all of its main systems such as air supply, turbocharging, fuel injection, valve train and exhaust system. GT-POWER is used.

- 1D Thermal Network: Determines the transfer, distribution and dissipation of the heat by the engine model through its coolant and oil circuits. It is integrated into the 1D Engine Model.

- Detailed Combustion Model: Calculates the combustion and its emissions using a 0D Stochastic Reactor Model (SRM) approach, in which the air-fuel mixture properties are represented by particles using LOGEengine. It is coupled with the 1D Engine Model.

3D In-Cylinder Simulation: Simulates the mixture formation of the engine cylinder with focus on turbulence and homogeneity. This is performed by RICARDO VECTIS. Simulation Environment: Manages the communication of the different simulation approaches and decides on the start of a 3D In-Cylinder Simulation. Starts the process routine for such a simulation or uses a previous simulation from the database. SIMULINK is used for the management of the simulation environment

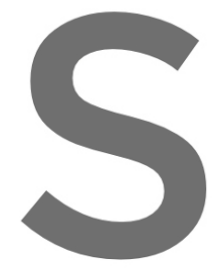

\section{The transient driving cycle is simulated b based on a gas exc and the combustion detailed combustio process to calculate the} quently, the cylinder mation and are provided by the one-dimensional thermal network. In order to achieve a higher

lences also have to be taken into account. These information are provided by three-dimensional in-cylinder simulations. Therefore, one cylinder of the engine is modelled. The entire simulation environment is controlled by a driver system, which also interacts with the various simulation approaches and decides on the need for three-dimensional in-cylinder simulations. If required, a three-dimensional in-cylinder simulation is restarted or a previous one is used. All of these different simulation approaches have their advantages and disadvantages. The developed simulation tool uses and combines the individual advantages of the various simulation approaches, which are presented in more detail below.

\subsection{Detailed Combustion Model}

For this project the SRM model is used to simulate the whole combustion process and the emission formation. This model is based on an approach of the Probability Density Function (PDF) for turbulent reactive flows, which enables a detailed chemical consideration [5]. It also contains sub-models for turbulent mixing and convective heat transfer, whereby the inhomogeneities inside the cylinder are taken into account with regard to species composition and tem- 
perature. The greatest strength of the SRM is its ability to qualitatively predict trends in emission formation in a reasonable amount of time [6].

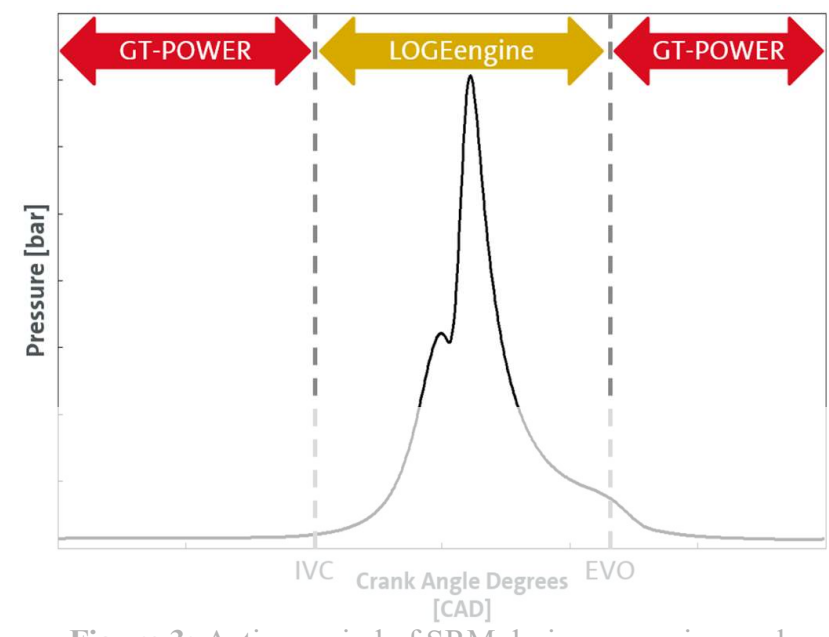

Figure 3: Active period of SRM during an engine cycle

As soon as the Inlet Valves Close (IVC), an exchange of certain species takes place between the gas exchange simulation and the detailed combustion model (see figure 3). The subsequent combustion simulation then takes place using the SRIM model, wherein the combustion chamber is divided into tially discretized (s the zones. Initially, zone. During the com figure 4). The con the burned zone. This process is purely stochastic, while both zones are assumed to be statistiRegister for free atmatens mix with each other. The mixing time $(\tau)$ indicates the frequency of the mixing between the particles. Each particle is discretized by its temperature, chemical composition and mass. It represents a point in phase-space for species mass fraction and temperature. The particle composition can vary within the cylinder [7]. The particles describe the composition of the gas mixture using a PDF (see figure 4). Thereby, each particle mass is defined by a Mass Density Function (MDF). For solving the mass and temperature transitions, the transport equations for the MDF is used [8].
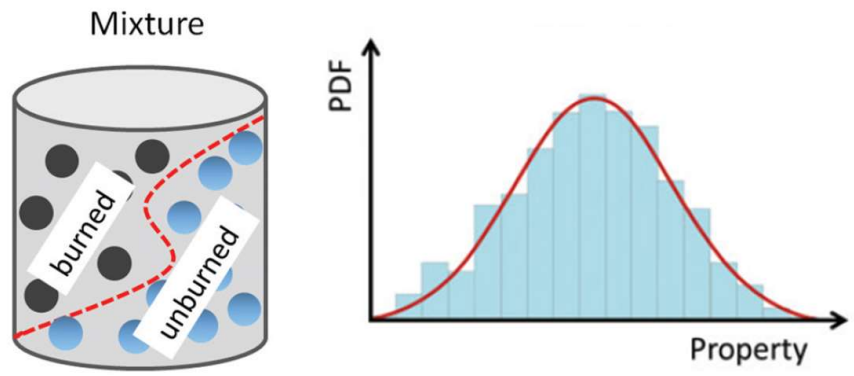

Figure 4: Concept of SRM within LOGEengine [7] 
When the Exhaust Valves Open (EVO), the information from the combustion simulation are transferred back to the 1D gas exchange simulation (see figure 3). It must be mentioned that the SRM model approach simplifies the combustion process. Local inhomogeneities during the combustion process are limited or not taken into account.

\subsection{One-Dimensional Engine Model and Thermal Network}

A one dimensional flow solver is used to simulate complete engines, which can be very complex and consist of multiple sub-models (see figure 5). This software tool allows the user to simulate engines under realistic conditions like stationary or transient runs and takes the cylinder motion, the combustion, the gas composition and the gas and component temperatures into account. Hereby, the gas flow in the entire engine is calculated as a function of time in the different sub-models by the Navier-Stokes equations. Nevertheless, experimental empiricism and curve fitting from tabular data are needed to properly calibrate the gas exchange model.
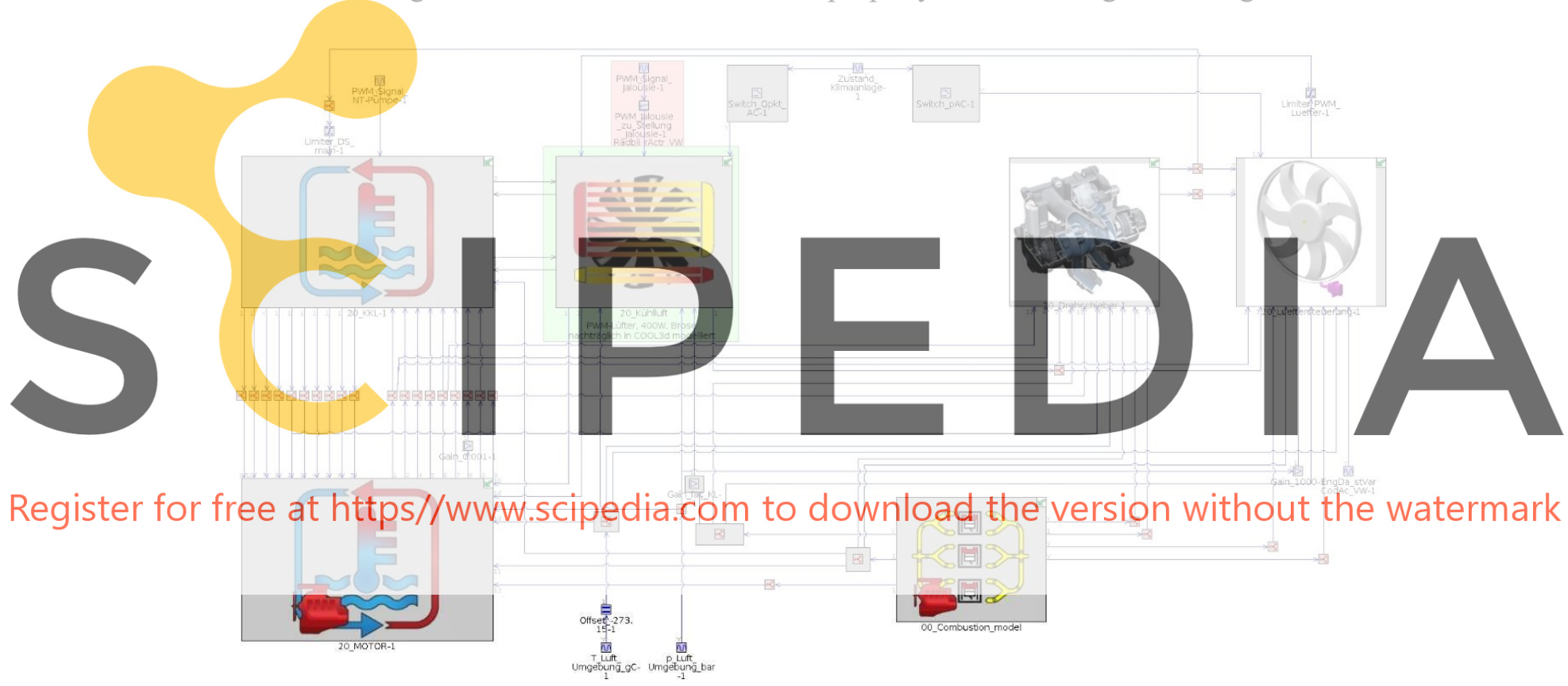

Figure 5: Flow model of the engine with its sub-models

The engine geometry consists of various pipes and flowsplits, which are the main parts of such a gas exchange simulation. Certain components of the engine (e.g. cylinders, turbochargers, aftertreatment devices, etc.) are represented by models and tables in order to calculate the required values (e.g. pressure, heat dissipation, mass flow, efficiency, etc.). The flow model is solved while maintaining the continuity, momentum and energy equations, whereby all quantities are mean values over the flow direction. The equations then form a system of non-linear differential equations of the second order, which the software solves [9]. For this purpose, the engine model is discretized into volumes. Flowsplits are represented by single volumes and pipes are divided into one or more volumes that are connected to other volumes by boundaries. Thereby, it is assumed that the scalar variables such as pressure, temperature, density, internal 
energy, enthalpy and species concentrations are uniform over each volume. Based on these conditions, the vector variables such as mass flow, speed and mass fraction can be calculated for each boundary. Figure 5 shows the flow model of the engine in which the driving cycle is integrated.

The detailed combustion model and the flow model are connected via an interface. Advanced settings can be made in the detailed combustion model interface, which are described in detail in the LOGEengine manual [10]. When the flow model reaches the point of the IVC (see figure 3 ), all information required for the combustion process are transferred to the detailed combustion model (see figure 6). Now the detailed combustion model performs the combustion calculation. Just before EVO, the detailed combustion model transfers the results of the combustion calculation back to the fluid model. Based on the combustion results, the flow model calculation continues. As soon as the IVC is reached again, the process is repeated.

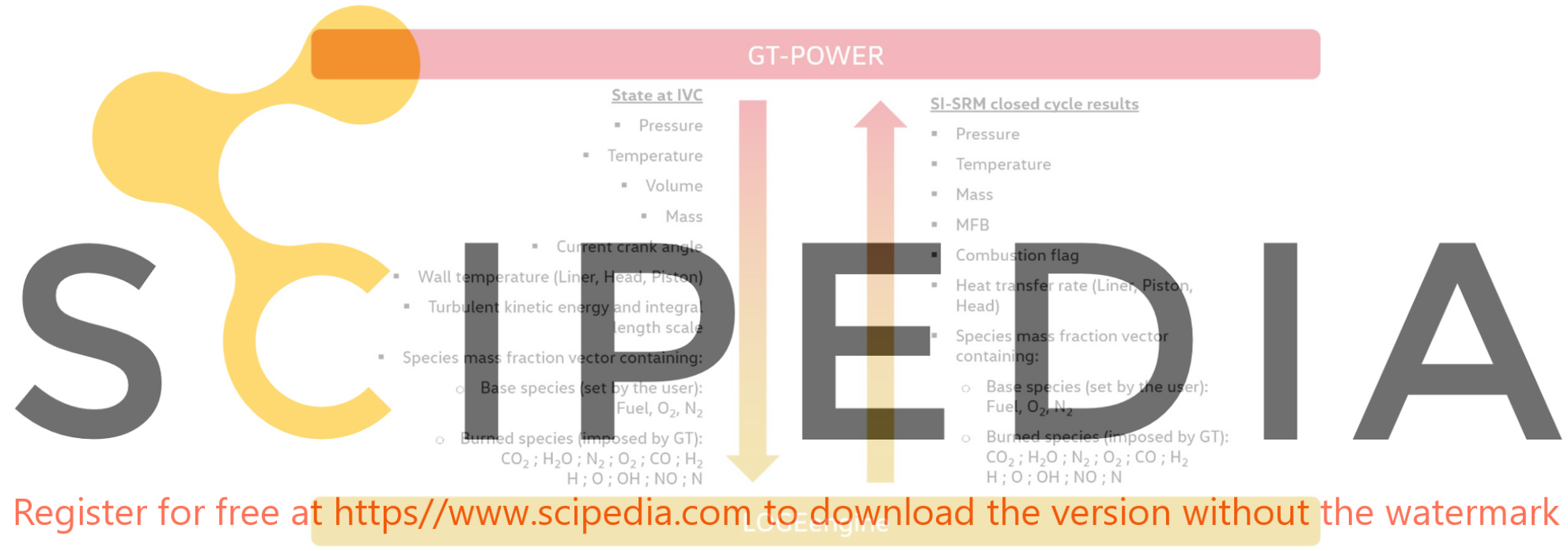

Figure 6: Data communication between GT-POWER and LOGEengine

The flow model and the software also have some drawbacks. In many parts of the real engine there is a three-dimensional flow field that is anything but uniform in the cross-sections. It is therefore necessary to extend this flow solver by coupling it with external software (see chapter 2.3). The software control modules are also limited by their flexibility and functionality, which is why this function is taken over by an external software (see chapter 2.4).

\subsection{Three-Dimensional In-Cylinder Simulation}

CFD is used for different engine designs and optimization stages. This technique is very powerful and used to analyze fluid flow, heat transfer and associated phenomena by computerbased simulations. In particular, the engine performance depends on the combustion system and therefore requires precise knowledge of the conditions in the combustion chamber, which can be analyzed by high resolution results from CFD simulations. These types of simulations are therefore predestined to resolve the effects of turbulences and the analysis of mixture formation and combustion processes. 
All CFD codes are based on numerical algorithms to solve the fluid flow problems. The fundamental equations governing the conservation of mass, momentum, energy and chemical species are solved using the finite-volume method. The equations are converted into numerically solvable differential equations by discretization methods [11]. This discretized equation system is solved with iterative methods, using the Reynolds' approach and inserting it into the Navier-Stokes equations. Time averaging is then performed to generate the Reynolds-Averaged Navier-Stokes Equations (RANS). These conservation equations can be solved with an acceptable numerical effort, whereby the Reynolds stress tensor leads to a "closing problem of the turbulence" [12]. In order to obtain a closed and thus solvable system of equations, semi-empirical assumptions in the form of statistical turbulence models like the k- $\varepsilon$-model are utilized. It is a two-equation model that is characterized by a partial differential equation and an algebraic equation [13]. Further information can be found in [14,15]. Each code has its own user interface to prepare the setup and to examine the results. The main elements of all codes are a pre-processor, a solver and a post-processor. The pre-processor handles all inputs to a flow problem, such as geometry definition, mesh preparation and spray creation. The results can then be yiewed with the post-processor and further investigations can be carried out.

CFD simulations are highly complex and cause great simulation costs. Therefore, the costbenefit analysis for CFD simulations must always be taken into account. Before the examined fluid flow problem can be solved by the computer, the user has to set up the simulation. The

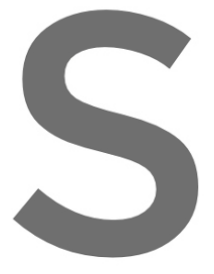
simulation tool de required data for the 1 tion and the creatio lation with moving a general cell size of $2 \mathrm{~mm}$, this study has to
mulation in an aut
ion of the setup fi
es. The computati
ille regions of in puter, the user has
fulfill the user's
tomated fashion.
ile and the spray
ional domain is spat is transient and has moving boundaries, the valve timings and lift profiles must be taken into

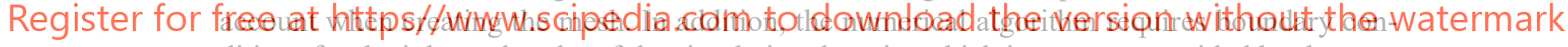
ditions for the inlet and outlet of the simulation domain, which in turn are provided by the onedimensional engine model. Moreover, wall temperatures from the one-dimensional thermal network are needed. Finally, the spray file is created by information of the spray strategy such as fuel mass, start of injection and injection pressure. Further information can be found in [16].

Due to a high CPU time, a simplified CFD setup is used: only one of four cylinders is simulated in a range between the maximum lift of the exhaust valves and the ignition point. Figure 6 shows the CFD model of the engine with its intake (blue) and exhaust (red) valves within the fuel injection phase. Thus, the CFD provides information about the initial condition and the turbulent mixing time that can be used by the detailed combustion model to increase the accuracy of the simulated emissions (see chapter 2.1). 


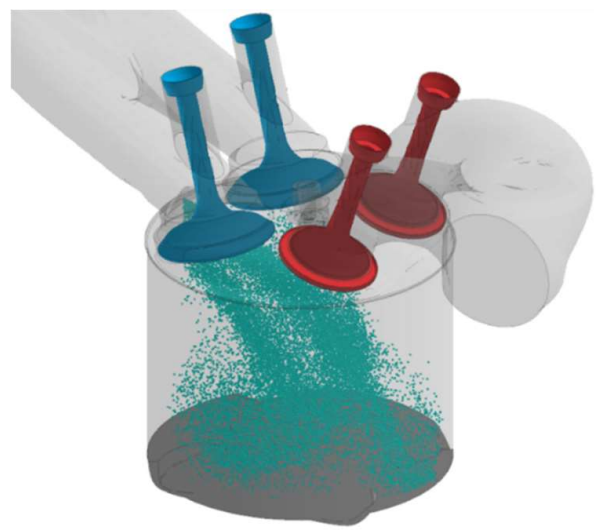

Figure 7: 3D in-cylinder mixture formation process

\subsection{Driver system}

The driver system has two main functions in the simulation tool. On the one hand, it represents an interface between the individual software products and ensures a smooth exchange of results. On the other hand, it has to take over the tasks of the user to set up the CFD simulation. This includes choosing the starting point for a new CFD run and monitoring the CFD procedure.

Figure 8 shows the simulation environment in which the engine model is implemented as a Functional Mockup Unit (FMU). The FMU is integrated on the left-hand stde, which forwards the output values to the right-hand side. On the right-hand side, the variables are proc regarding the CFD simulation. For abetter understanding the interface is colored. Gre can be changed by the user. Orange areas can should not be changed, because these sub-models control the
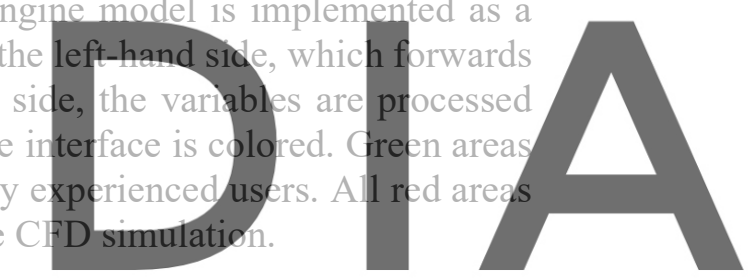

Register for free at https//www.scipedia.com to download the version without the watermark

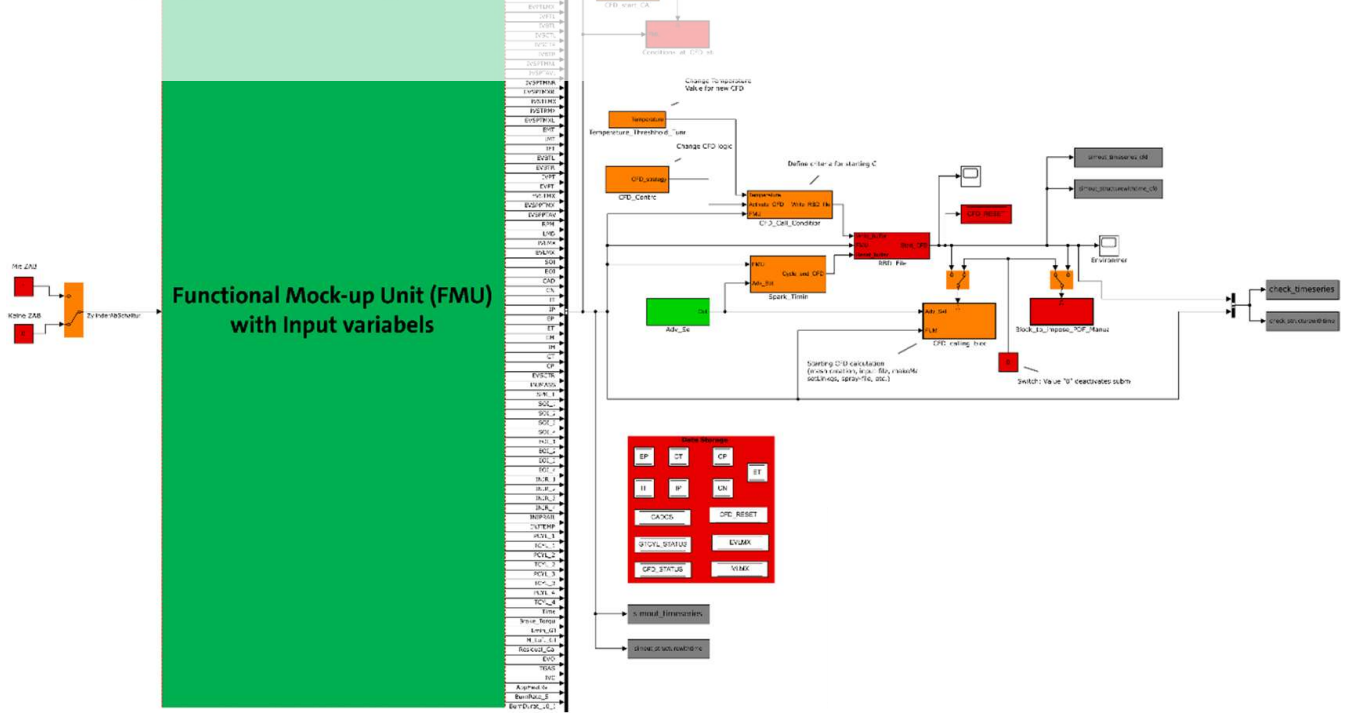

Figure 8: Simulation environment 
Different data are needed and have to be prepared and transferred to the CFD setup automatically. Figure 9 shows the automatic process routine for CFD simulations. First, the required data are collected from the one-dimensional engine model. Afterwards, initial values such as temperatures, pressures and engine speed are written to the CFD input file. The spray file is then created using the information about the fuel mass, the injection pressure, the start of injection and the injection strategy. In addition, the mesh creation is performed. When all the data are prepared for the CFD simulation, the fluid flow problem is solved on the High Performance Computer (HPC). A plausibility check is carried out at the end of the CFD simulation. After the CFD simulation is finished, the major results have to be transferred to the detailed combustion model, whereby the local inhomogeneities in the cylinder should be preserved (see figure 9). The CFD result is represented by almost 200.000 cells, which now have to be converted into an SRM result with only a few hundred particles. The aim of this "translation" is to create particles, which only consist of neighboring cells from CFD and contain information about the composition of the mixture formations that are specific for this zone. This process is also carried out automatically.
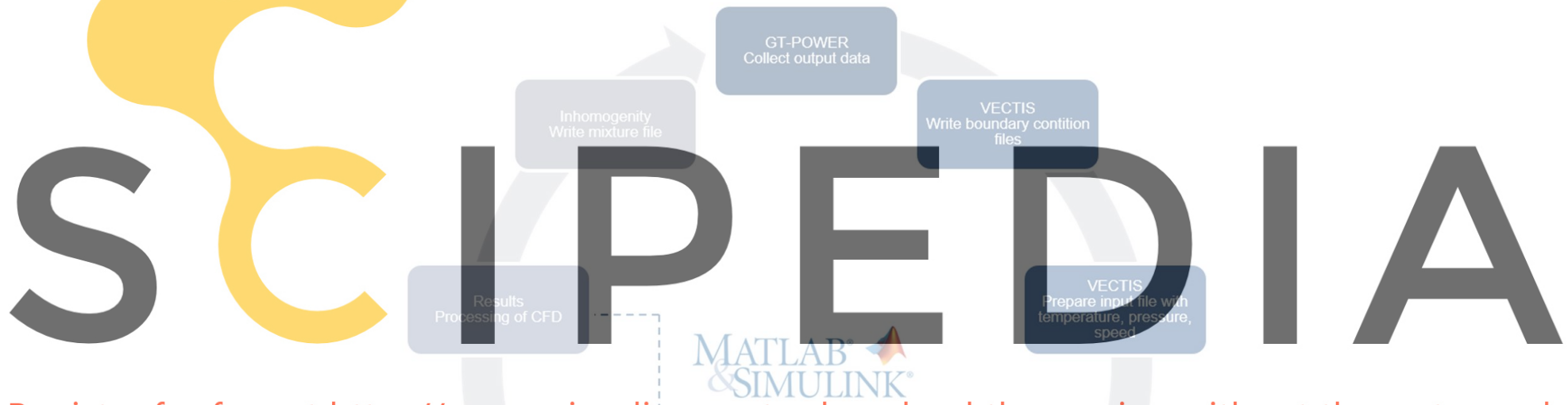

\section{Register for free at https//www.scipedià.com to do}

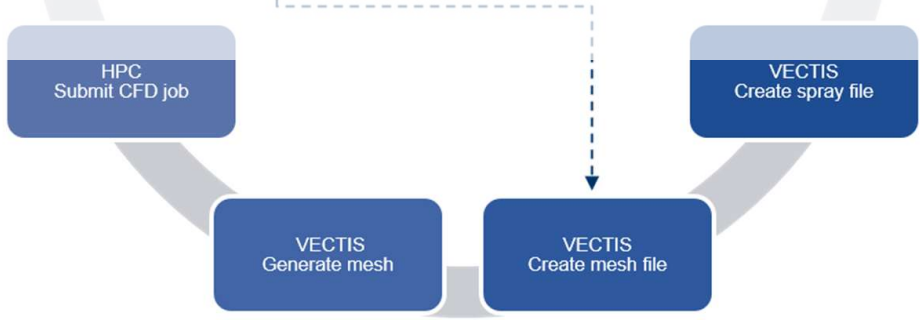

Figure 9: Automatic process routine for CFD simulation

\section{SIMULATION INTERACTION}

Figure 10 shows a simplified operating plan between the detailed combustion model, the flow model and the CFD simulation. As explained in paragraph 2.4 the driver system ensures the appropriate communication between the different software programs and makes the decision if and when a new CFD simulation has to be started. The criteria for starting a new CFD simulation are determined in advance using engine control parameter variations at three stationary operating points and then transferred to the driver system. These criteria are control 
parameters such as gas temperature at spark timing, engine torque, engine speed, valve timing, injection pressure and start of injection, which have an influence on the mixture distribution in the cylinder.

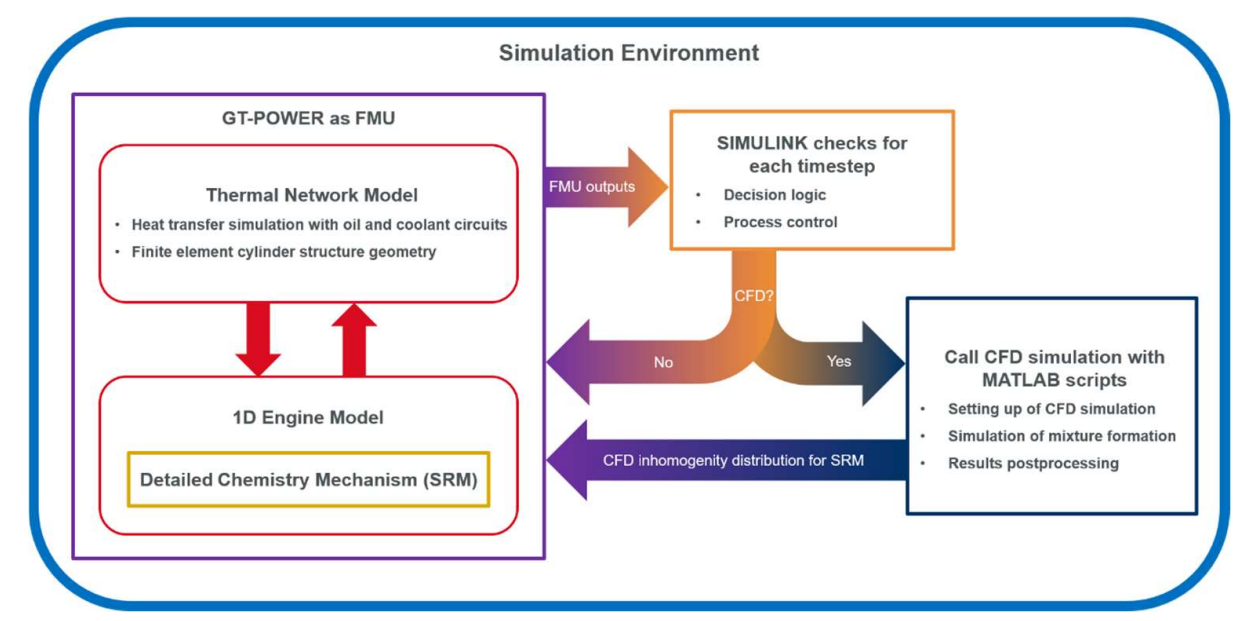

Figure 10: Interaction of the individual simulation programs

Before the simulation environment can be used, some preparatory work has to be done. The interface of the detailed combustion model and the examined driving cycle are integrated into the engine model (see figure 2). Afterwards the flow model is compiled into an FMU and used inside the driver system. The FMU is a standardized interface, which can be used to couple different simulation software. The driver system contains all the logical paths for setting up and processing CFD simulations (see figure 8). Finally, the user has to select the starting point in the driving profile to be examined. Moreover, there are three different ways to use the CFD simulation during the investigation of the driving cycle, which can be selected by the user. Depending on the logic, the CFD can be started in the examined area at certain time steps, in a defined interval or over the entire period. After this decision has been made, the simulation environment can be started.

During the simulation, the driver system processes the FMU output information and decides for each time step whether a CFD simulation is required with regard to the user selection (see figure 10). If the logic comes to the conclusion that a CFD simulation is necessary, an internal process is started (see figure 9). The driver system collects all the data and transfers them into a CFD format. Then, the CFD simulation is started and monitored. After completing the CFD calculation, the results are automatically processed and exported to the detailed combustion model (see chapter 2.1). From that moment on, the detailed combustion model uses the information of the mixture distribution as initial conditions to simulate the emissions. In the course of the driving cycle simulation, this process starts again if the driver system detects differences compared to the previous CFD simulation. This ensures that the detailed combustion model always has up-to-date information about the inhomogeneities of the mixture in the cylinder. 


\section{CONCLUSIONS}

For the investigation of the emission levels during the cold start and the following transient operation of an engine, an automated simulation tool is created. This simulation tool combines different programs and thereby makes a compromise between speed and accuracy. The onedimensional engine model is used to simulate the WLTP cycle. The combination with the detailed combustion model enables the emission values to be calculated with high accuracy based on detailed chemistry. In order to increase the accuracy of the detailed combustion model, threedimensional in-cylinder simulations are used to obtain detailed information on the mixture formation. The whole process is controlled by a driver system, which among other things starts a CFD simulation if necessary.

First test simulations for transient operations proved the credibility of the simulation tool by significantly increasing the accuracy of the emission predictions. Further improvements of the simulation tool will lead to comprehensive studies of emission levels and can be applied to find ways to reduce them.

\section{REFERENCES}

[1] Umweltbundesamt. Emissionen des Verkehrs. [September 20, 2020]; Available from: www.umweltbundesamt.de/daten/verkehr/emissionen-des-verkehrs\#pkw-fahren-heute-klima-und-umweltvertraglicher.

[2] LMC Automotive. Global Light Vehicle Forecast. [October 25, 2020]; Available from: lmc-auto.com/wpcontent/uploads/2020/06/LMCA-G-LVF-Leaflet.pdf.

[3] van Basshuysen R, Schäfer F. Handbuch Verbrennungsmotor: Grundlagen, Komponenten, Systeme, Perspektiven. 8th ed; 2017.

[4] Volkswagen AG. WLTP: Neue Standards für Verbrauchswerte. [November 10, 2020]; Available from: www.volkswagen.de/de/besitzer-und-nutzer/wichtige-kundeninformationen/rechtliches/wltp.html.

[5] Kraft M, Maigaard P, Mauß F, Christensen M, Johansson B. Investigation of Combustion Emissions in a HCCI Engine-Measurements and A New Computational Model; 2002.

[6] Mosbach S, Kraft M, Zhang HR, Kubo S, Kim K-O. Der Weg zu einem detaillierten Rußmodell für Verbrennungsmotoren. MTZ Motortech Z 2009;70(5):408-12.

[7] Pasternak M, Mauss F, Sens M, Riess M, Benz A, Stapf KG. Gasoline engine simulations using zero-dimensional spark ignition stochastic reactor model and three-dimensional computational fluid dynamics engine model. International Journal of Engine Research 2015;17(1):76-85.

[8] Pasternak M, Mauss F, Xavier F, Rieß M, Sens M, Benz A. 0D/3D Simulations of Combustion in Gasoline Engines Operated with Multiple Spark Plug Technology. In: SAE Internationals, editor. SAE 2015 World Congress \& Exhibition. Warrendale, United States; 2015.

[9] Gamma Technologies. GT-Suite: Flow Theory Manual; 2017.

[10]LOGE AB. Manual LOGEengine Version 3.0: Scientific Software For Modelling Of Chemical Kinetic Systems; 2017.

[11] Ferziger JH, Peric M, Street RL. Numerische Strömungsmechanik. 2nd ed; 2020.

[12] Breuer M. Direkte numerische Simulation und Large-Eddy Simulation turbulenter Strömungen auf Hochleistungsrechnern. Zugl.: Erlangen-Nürnberg, Univ., Habil.-Schr., 2001. Aachen: Shaker Verlag; 2002.

[13] Bardina JE, Huang PG, Coakley TJ. Turbulence Modeling Validation, Testing, and Development. [January 13, 2021]; Available from: ntrs.nasa.gov/citations/19970017828.

[14] Laurien E, Oertel jr. H. Numerische Strömungsmechanik: Grundgleichungen und Modelle - Lösungsmethoden - Qualität und Genauigkeit. 5th ed. Wiesbaden, s.1.: Springer Fachmedien Wiesbaden; 2013.

[15] Versteeg HK, Malalasekera W. An introduction to computational fluid dynamics: The finite volume method. 2nd ed. Harlow: Pearson/Prentice Hall; 2007.

[16] Ricardo Software. VECTIS User Manual (Version 2018.1). Belleville, MI; 2018. 